九州大学学術情報リポジトリ

Kyushu University Institutional Repository

\title{
Switching effect in Cu:TCNQ charge transfer- complex thin films by vacuum codeposition
}

Oyamada, Takahito

Department of Photonics Materials Science, Chitose Institute of Science and Technology (CIST)

Tanaka, Haruo

Rohm Co., Ltd.

Matsushige, Kazumi

International Innovation Center (IIC), Kyoto University

Sasabe, Hiroyuki

Department of Photonics Materials Science, Chitose Institute of Science and Technology (CIST)

他

http://hdl. handle. net/2324/19452

出版情報: Applied Physics Letters. 83 (6), pp. 1252-1254, 2003-08-11. American Institute of Physics

バージョン :

権利関係: Copyright 2003 American Institute of Physics. This article may be downloaded for personal use only. Any other use requires prior permission of the author and the American Institute of Physics. 


\title{
Switching effect in Cu:TCNQ charge transfer-complex thin films by vacuum codeposition
}

\author{
Takahito Oyamada \\ Department of Photonics Materials Science, Chitose Institute of Science and Technology (CIST), \\ 758-65 Bibi, Chitose, Hokkido, 066-8655, Japan \\ Haruo Tanaka \\ Rohm Co., 21 Saiin Mizosaki, Ukyo Kyoto 615-8585, Japan \\ Kazumi Matsushige \\ International Innovation Center (IIC), Kyoto Univ., IIC, Yoshida-Honmachi, Sakyo, Kyoto 606-8501, Japan \\ Hiroyuki Sasabe and Chihaya Adachia) \\ Department of Photonics Materials Science, Chitose Institute of Science and Technology (CIST), \\ 758-65 Bibi, Chitose, Hokkido, 066-8655, Japan
}

(Received 21 April 2003; accepted 14 June 2003)

\begin{abstract}
We demonstrate the operation of an organic switching device using a uniform poly-crystalline $\mathrm{Cu}: 7$, 7, 8, 8-Tetracyanoquinodimethane (TCNQ) charge transfer (CT)-complex thin film that is prepared by vacuum vapor codeposition. Characteristic CT-absorption at $\lambda=600-1200 \mathrm{~nm}$ was observed in the complex film in the UV-visible spectrum and the cyano stretching peak in the IR spectrum shifted to a higher (more than $29 \mathrm{~cm}^{-1}$ ) wave number than that of a pristine TCNQ film, suggesting the formation of a CT-complex in the evaporated thin film. Reproducible electrical switching characteristics were observed in the indium tin oxide/ $\mathrm{Al} /\left(\mathrm{Al}_{2} \mathrm{O}_{3}\right) / \mathrm{Cu}$ :TCNQ/Al structure. The device exhibited a clear threshold from low impedance to high impedance at an applied voltage of $10.0 \pm 2.0 \mathrm{~V}$ and a reverse phenomenon at a negative bias of $-9.5 \pm 2.0 \mathrm{~V}$. In this study, we demonstrate that a thin $\mathrm{Al}_{2} \mathrm{O}_{3}$ layer between the aluminum $(\mathrm{Al})$ anode and $\mathrm{Cu}$ :TCNQ layers creates reproducible switching. (C) 2003 American Institute of Physics. [DOI: 10.1063/1.1600848]
\end{abstract}

There has been a growing interest in organic electronic devices such as organic light emitting diodes (OLEDs), ${ }^{1}$ organic solar cells, ${ }^{2}$ organic transistors, ${ }^{3}$ and organic switching devices $^{4-13}$ due to the unique electrical and optical properties of organic materials. Recently OLEDs, in particular, have demonstrated significant improvements that have provided highly efficient full-color-display applications. The introduction of thin film transistors (TFTs) is indispensable and high performance organic TFTs have been anticipated for the active matrix driving of OLED displays. In this letter, we focus on a switching phenomenon using a $\mathrm{Cu}$ :7,7,8,8Tetracyanoquinodimethane (TCNQ) charge transfer (CT) complex, which will be useful for organic TFT applications.

Observation of switching phenomena by a Cu:TCNQ CT complex was first reported by Potember et al. ${ }^{4-7} \mathrm{Cu}: T C N Q$ CT-complex films with a grain size of a few micrometers were formed with a solution growth method on a precleaned $\mathrm{Cu}$ substrate that was dipped into a solution of degassed acetone: acetonitrile (1:1) saturated with TCNQ. ${ }^{5} \mathrm{Cu}$ :TCNQ films that were $\sim 10 \mu \mathrm{m}$ thick were formed with this method having a poly-crystalline morphology on a $\mathrm{Cu}$ substrate and their switching characteristics were first reported with a sandwiched structure of $\mathrm{Cu} / \mathrm{Cu}: \mathrm{TCNQ} / \mathrm{Al}$. However, most devices have a serious problem with homogeneity in the $\mathrm{Cu}$ :TCNQ films, leading to a lack of reproducibility in device characteristics. To solve these problems, we fabricated a $\mathrm{Cu}$ :TCNQ switching device by vacuum codeposition which

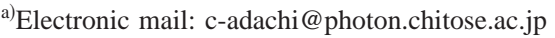

allows precise control of $\mathrm{Cu}$ and TCNQ contents. In this letter, we report on the reproducible switching characteristics of a Cu:TCNQ codeposited film.

Organic and metal layers were deposited by highvacuum $\left(1 \times 10^{-3} \mathrm{~Pa}\right)$ thermal evaporation onto a clean glass substrate pre-coated with an indium tin oxide (ITO) layer $(300 \mathrm{~nm}$ thick) with a sheet resistance of $\sim 20 \Omega / \square$. The substrate was degreased with solvents and cleaned in a UV-ozone chamber (Nippon Laser \& Electronics Lab., NLUV253). First, a 20-nm-thick Al layer was thermally deposited on an ITO coated glass substrate and successively transferred into an UV-ozone chamber (12 $\left.\mathrm{min}, \mathrm{O}_{2} 1 \mathrm{~atm}\right)$ to form a thin $\mathrm{Al}_{2} \mathrm{O}_{3}$ on an $\mathrm{Al}$ layer. We found that this procedure to form the thin $\mathrm{Al}_{2} \mathrm{O}_{3}$ layer was crucial to obtain reproducible switching characteristics. Next, a 100-nm-thick Cu:TCNQ layer was deposited via thermal codeposition onto the $\mathrm{Al}_{2} \mathrm{O}_{3} / \mathrm{Al} / \mathrm{ITO}$ layer. Finally, a shadow mask with $1 \mathrm{~mm}$ diameter openings was used to define the cathode consisting of a 100-nm-thick Al layer, and then the ITO/Al/ $\left(\mathrm{Al}_{2} \mathrm{O}_{3}\right) / \mathrm{Cu}$ :TCNQ/Al device structure was completed. Here, we stress that when we fabricate the devices without breaking vacuum, it was very hard to obtain reproducible switching effect, suggesting formation of a thin $\mathrm{Al}_{2} \mathrm{O}_{3}$ layer is responsible for the switching effect. We fabricated an ITO/ $\mathrm{Al}_{2} \mathrm{O}_{3} / \mathrm{Cu}$ :TCNQ/Al device in a similar manner where a thin $\mathrm{Al}_{2} \mathrm{O}_{3}$ layer was directly deposited on an ITO substrate by rf sputtering $\left(100 \mathrm{~W}, \sim 2.4 \times 10^{-1} \mathrm{~Pa}\right)$. In these devices, various deposition ratios of Cu:TCNQ, namely, 0:1 (0 atm/ mol \%), 1:2 (33 atm/mol \%), 1:1 (50 atm/mol \%), 3:2 (60 

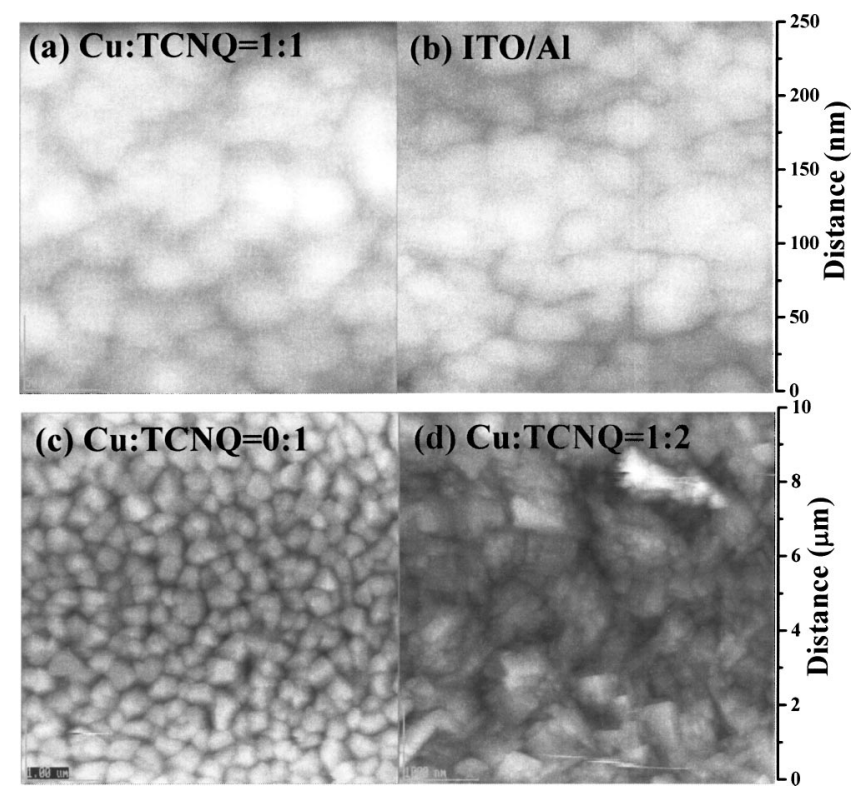

FIG. 1. AFM photomicrographs of $\mathrm{Cu}$ :TCNQ layers $(100 \mathrm{~nm})$ on aluminum (Al) layer with $\mathrm{Cu}$ TCNQ ratios of (a) 1:1, (c) 0:1, and (d) 1:2. Deposited aluminum layer on indium tin oxide layer (b) is also shown for reference.

atm/mol \%), 2:1 (66 atm/mol \%) and 4:1 (80 atm/mol \%) were employed.

Current density $(J)$-voltage $(V)$ characteristics were measured using an HP4145 semiconductor parameter analyzer. Before $J-V$ measurement, aging operation was performed. We first applied a cyclic triangular voltage with a minimum voltage of $V_{\min }=0 \mathrm{~V}$ and a maximum voltage of $V_{\max }=1 \mathrm{~V}$ with a frequency of $1 \mathrm{~Hz}$ for a few minutes and then increased $V_{\max }$ from 1 to $8 \mathrm{~V}$ in turn. The devices settled in high impedance mode during this. Aging is indispensable to induce switching characteristics and all devices undergo this.

We first investigated the film quality of $\mathrm{Cu}$ :TCNQ codeposited films on ITO/Al substrates. Atomic force microscopy (AFM) revealed a uniform poly-crystalline texture at a Cu:TCNQ deposition ratio of 1:1 (Fig. 1). The film had a grain size of $\sim 50 \mathrm{~nm}$ and a depth profile of $\sim 20 \mathrm{~nm}$, which coincided well with the surface structure of the underlying Al

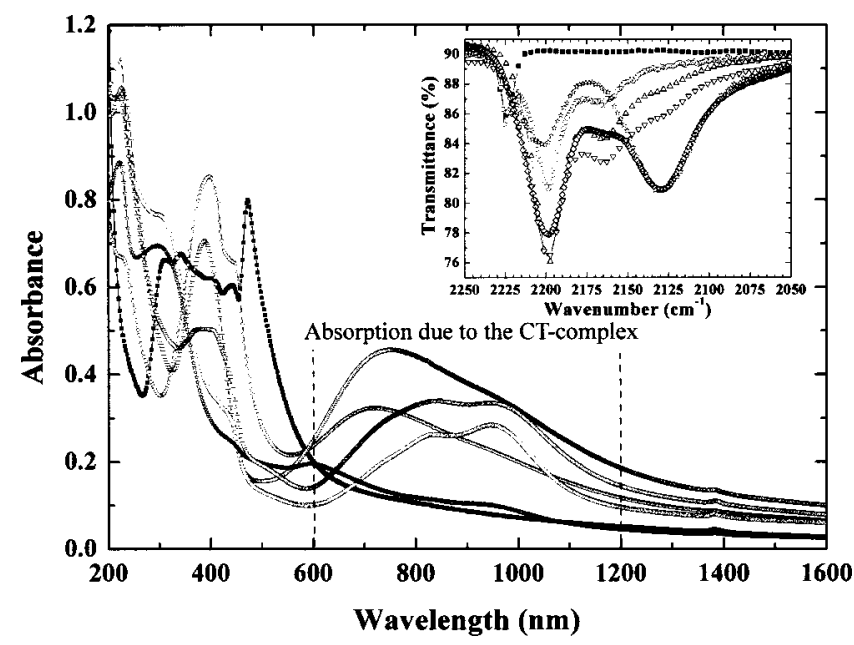

FIG. 2. Absorption spectra and infrared spectra (inset) of Cu:TCNQ CTcomplex thin films with various Cu:TCNQ ratios of $\mathrm{Cu}$ :TCNQ (atom:mol) $=0: 1(\square), 1: 2(\bigcirc), 1: 1(\triangle), 3: 2(\nabla), 2: 1(\diamond)$, and $4: 1(\succsim)$.

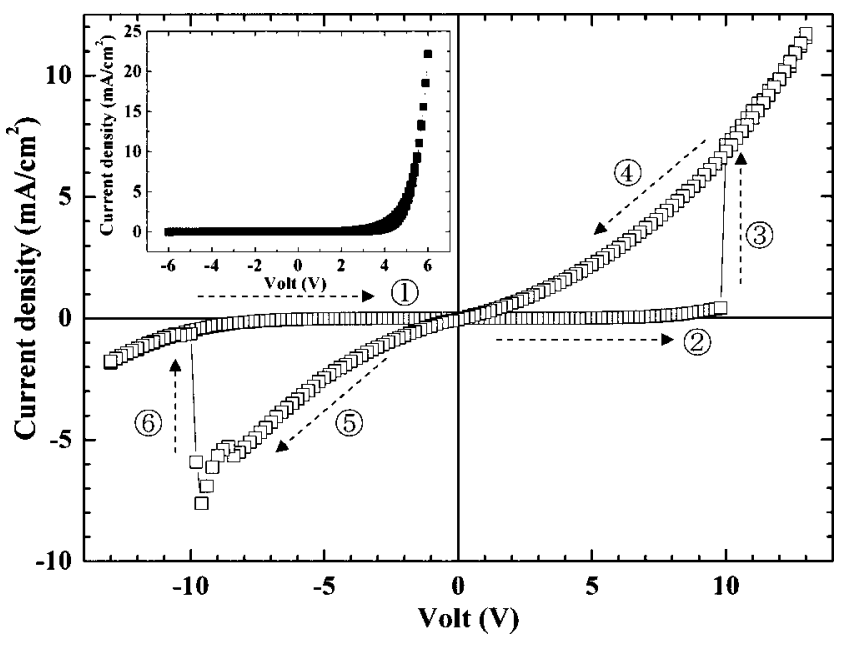

FIG. 3. $J-V$ characteristics of an ITO (300 nm)/Al $(20 \mathrm{~nm}) /$ $\left(\mathrm{Al}_{2} \mathrm{O}_{3}\right) / \mathrm{Cu}: \mathrm{TCNQ}(1: 1,100 \mathrm{~nm}) / \mathrm{Al}(100 \mathrm{~nm})$ device. (Inset) $J-V$ characteristics of an ITO $(300 \mathrm{~nm}) / \mathrm{Cu}: \operatorname{TCNQ}(1: 1,100 \mathrm{~nm}) / \mathrm{Al}(100 \mathrm{~nm})$ device.

layer, resulted in a uniform dense poly-crystalline $\mathrm{Cu}$ :TCNQ layer. At Cu:TCNQ deposition ratios of $0: 1$ and 1:2, however, large uneven poly-crystalline textures with a characteristic grain size of $\sim 2 \mu \mathrm{m}$ were observed, resulting in failure to deposit a uniform metallic cathode electrode. Consequently, we employed a Cu:TCNQ ratio of 1:1 to fabricate the devices.

The absorption spectrum of Cu:TCNQ codeposited films confirms the formation of a CT complex. Figure 2 summarizes the absorption spectra for pristine TCNQ and Cu:TCNQ (1:2, 1:1, 3:2, 2:1, and 4:1) deposited films. A characteristic CT band was observed at $600-1200 \mathrm{~nm}$, while there was no significant absorption in the pristine TCNQ film. There was also a cyano stretching peak (2200-2160 $\mathrm{cm}^{-1}$ ) for the complex films (Cu:TCNQ=1:2, 1:1, and 3:2) in the IR spectra and this shifted to a higher (more than 29 $\mathrm{cm}^{-1}$ ) wave number than that for the pristine TCNQ (2226 $\mathrm{cm}^{-1}$ ) (inset of Fig. 2). In the Cu:TCNQ with deposition ratios of 2:1 and 4:1, additional vibration at $2129 \mathrm{~cm}^{-1}$ was also observed in addition to absorption at $2200 \mathrm{~cm}^{-1}$.

Figure 3 reveals characteristic electrical switching of an ITO/Al/Cu:TCNQ/Al device. The device has a clear threshold from low impedance to high impedance at an applied voltage of $10.0 \pm 2.0 \mathrm{~V}$ and a reverse phenomenon at a negative bias of $-9.5 \pm 2.0 \mathrm{~V}$, when we progressively apply a voltage as indicated by the circled numbers. This characteristic switching phenomenon was observed more than 1000 times. However, we observed no switching effect in the ITO/ $\mathrm{Cu}: \mathrm{TCNQ} / \mathrm{Al}$ device, suggesting that the Al layer plays an important role in switching (inset of Fig. 3).

Figure 4 has the switching characteristics of $\mathrm{Cu}$ :TCNQ devices with various Cu:TCNQ ratios. We observed the switching effect only with $\mathrm{Cu}$ :TCNQ concentrations of $1: 2$, $1: 1$, and $3: 2$ and no switching effect with concentrations of $0: 1,2: 1$, and $4: 1$. In particular, the Cu:TCNQ (1:1) thin film resulted in the largest ON/OFF ratio of $\sim 10^{3}$ at $5.0 \mathrm{~V}$. In the case of high $\mathrm{Cu}$ concentrations, on the other hand, $\mathrm{Cu}$ atoms presumably formed a conductive channel in the complex films, leading to the lack of a switching effect. Also, the lack of switching characteristics in the TCNQ neat layer suggests onse or copyright; see http://apl.aip.org/about/rights and permission 


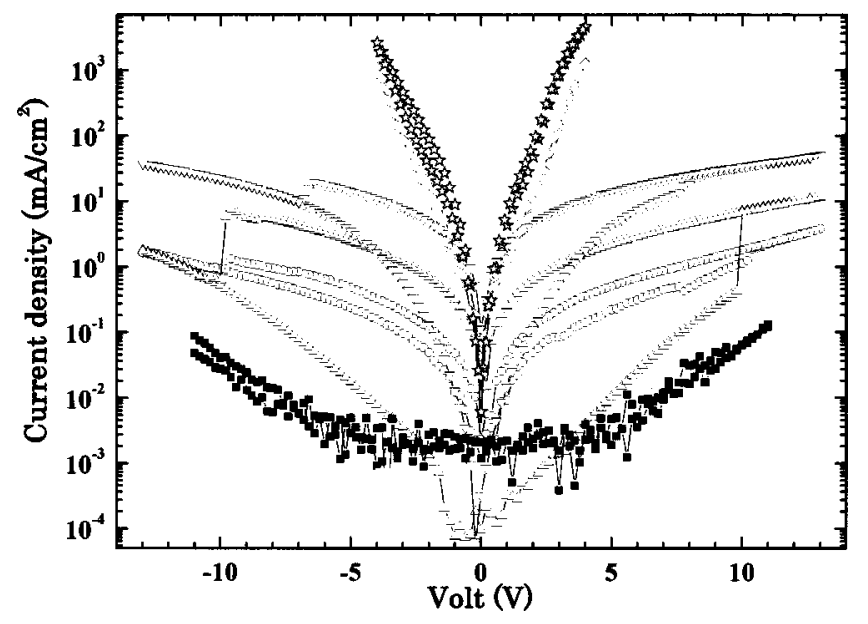

FIG. 4. $J-V$ characteristics of ITO $(300 \mathrm{~nm}) / \mathrm{Al} \quad(20 \mathrm{~nm}) /$ $\left(\mathrm{Al}_{2} \mathrm{O}_{3}\right) / \mathrm{Cu}$ :TCNQ $(1: 1,100 \mathrm{~nm}) / \mathrm{Al}(100 \mathrm{~nm})$ devices with various $\mathrm{Cu}: \mathrm{TCNQ}$ ratios; $\mathrm{Cu}: \mathrm{TCNQ}=0: 1(\boldsymbol{\square}), 1: 2(\bigcirc), 1: 1(\triangle), 3: 2(\nabla), 2: 1(\diamond)$, and 4:1 (灾).

that charge transfer between $\mathrm{Cu}$ and TCNQ is also responsible for switching.

To understand the switching mechanisms, we investigated the switching characteristics depending on thickness of the $\mathrm{Cu}$ :TCNQ layer and the anode electrodes. Here, we fixed $\mathrm{Cu}$ :TCNQ ratio at 1:1 because it had the best switching characteristics. Interestingly, the switching characteristics were almost independent of the Cu:TCNQ thickness (Fig. 5), suggesting that switching is basically an interfacial phenomenon between the electrode and the Cu:TCNQ layer. The anode materials are also crucial in switching. Here, instead of an $\mathrm{Al}$ anode, we employed a device structure of ITO/ $\mathrm{Al}_{2} \mathrm{O}_{3} / \mathrm{Cu}: \mathrm{TCNQ}(1: 1) / \mathrm{Al}$ where the $\mathrm{Al}_{2} \mathrm{O}_{3}$ layer was formed by rf sputtering to confirm its effect. This was because we found that it was necessary to form a thin $\mathrm{Al}_{2} \mathrm{O}_{3}$ layer through UV-ozone treatment to obtain reproducible switching characteristics. At $\mathrm{Al}_{2} \mathrm{O}_{3}$ thicknesses of $0,1.0,5.0,7.5$, 8.8 , and $10.0 \mathrm{~nm}$, we observed switching effects with 1.0 , 5.0, 7.5, 8.8, and 10.0-nm-thick $\mathrm{Al}_{2} \mathrm{O}_{3}$ layers, and a maximum ON/OFF ratio of $\sim 10^{4}$ with the 7.5-nm-thick $\mathrm{Al}_{2} \mathrm{O}_{3}$ layer. We did not observe any switching effects without an $\mathrm{Al}_{2} \mathrm{O}_{3}$ layer. Thus, these results indicate that a thin $\mathrm{Al}_{2} \mathrm{O}_{3}$ layer on an $\mathrm{Al}$ layer is responsible for the switching effect. Due to the large dielectric constant of the $\mathrm{Al}_{2} \mathrm{O}_{3}$ layer $(\varepsilon \sim 10)$, a high built-in field is formed between the $\mathrm{Al} / \mathrm{Al}_{2} \mathrm{O}_{3}$ and $\mathrm{Cu}$ :TCNQ layer which controls partial charge transfer $(\rho)$ between $\mathrm{Cu}\left(\operatorname{donor}^{+\rho}\right)$ and TCNQ $\left(\right.$ acceptor $\left.^{-\rho}\right)$. It is often observed that neutral TCNQ molecules provide a mixed valence state with existing TCNQ radical anions in TCNQ columns and mixed valence. TCNQ complexes are more conductive than charge transfer complexes with complete charge transfer. ${ }^{6-9}$ Thus, the external field would convert a significant amount of charge transfer Cu:TCNQ to neutral TCNQ with the application of a forward bias of 10.0 $\pm 2.0 \mathrm{~V}$ and then charge carriers would be subjected to tunneling injection through the thin $\mathrm{Al}_{2} \mathrm{O}_{3}$ layer into the $\mathrm{Cu}$ :TCNQ layer. However, the reverse switching phenom-

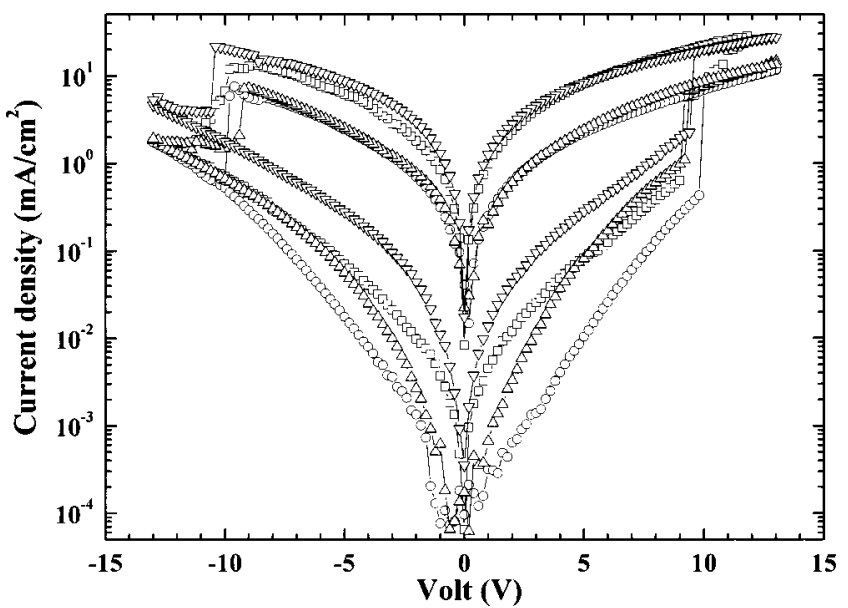

FIG. 5. $J-V$ characteristics of ITO $(300 \mathrm{~nm}) / \mathrm{Al} \quad(20 \mathrm{~nm}) /$ $\left(\mathrm{Al}_{2} \mathrm{O}_{3}\right) / \mathrm{Cu}$ :TCNQ $(1: 1, \mathrm{X} \mathrm{nm}) / \mathrm{Al}(100 \mathrm{~nm})$ devices depending on the $\mathrm{Cu}$ TCNQ thickness; i.e., $50(\square), 100(\bigcirc), 200(\triangle)$, and $300 \mathrm{~nm}(\nabla)$.

enon from neutral TCNQ into charge transfer $\mathrm{Cu}$ :TCNQ would occur with the application of a reverse bias of -9.5 $\pm 2.0 \mathrm{~V}$. Further researches into understanding the switching mechanism are currently in progress.

In summary, we demonstrated that it was possible to form uniform $\mathrm{Cu}$ :TCNQ CT-complex thin films by vacuum codeposition. A device with an ITO/Al/Cu:TCNQ/Al configuration with $\mathrm{Cu}$ :TCNQ (1:1) thin film demonstrated reproducible switching characteristics with a large ON/OFF ratio of $\sim 10^{4}$. We demonstrated that the interface of the $\mathrm{Al}$ anode and $\mathrm{Cu}$ :TCNQ layers is mainly responsible for high electric field due to the presence of a thin $\mathrm{Al}_{2} \mathrm{O}_{3}$ layer, leading to electrical switching. Both the formations of uniform $\mathrm{Cu}$ :TCNQ and the thin $\mathrm{Al}_{2} \mathrm{O}_{3}$ layers contribute to occurrence of the switching effect.

This work was supported by Integrated Industry Academia Partnership (IIAP) projects from Kyoto University International Innovation Center and the Grant-in-Aid for Scientific Research of the Ministry of Education, Science and Sports in Japan for financial support of this research.

${ }^{1}$ Organic Light Emitting Devices, edited by J. Shinar (Springer, Berlin, 2003).

${ }^{2}$ Z. H. Kafafi, Proc. SPIE 4465 (2002).

${ }^{3}$ D. Fichou and Z. Bao, Proc. SPIE 4466 (2002).

${ }^{4}$ R. S. Potember, T. O. Poehler, and R. O. Cowan, Appl. Phys. Lett. 34, 405 (1979).

${ }^{5}$ R. S. Potember, T. O. Poehler, D. O. Cowan, A. N. Bloch, P. Brant, and F. L. Carter, Chem. Scr. 17, 219 (1981).

${ }^{6}$ R. S. Potember, T. O. Poehler, and R. C. Benson, Appl. Phys. Lett. 34, 405 (1982).

${ }^{7}$ R. S. Potember, T. O. Poehler, A. Rappa, D. O. Cowan, and A. N. Bloch, Synth. Met. 4, 371 (1982).

${ }^{8}$ Y. Iwasa, T. Koda, Y. Tokura, S. Koshihara, N. Iwasawa, and G. Saito, Appl. Phys. Lett. 55, 2111 (1989).

${ }^{9}$ S. Yamaguchi and R. S. Potember, Synth. Met. 78, 117 (1996).

${ }^{10}$ C. Sato, S. Wakamatsu, and K. Tadokoro, J. Appl. Phys. 68, 12 (1990).

${ }^{11}$ L. Ma, J. Liu, S. Pyo, and Y. Yang, Appl. Phys. Lett. 80, 362 (2002).

${ }^{12}$ L. Ma, S. Pyo, J. Ouyang, Q. Xu, and Y. Yang, Appl. Phys. Lett. 82, 1419 (2003).

${ }^{13}$ X.-C. Gao, D.-C. Zou, K. Fujita, and T. Tsutsui, Appl. Phys. Lett. 81, 4508 (2002) 